\title{
Endoscopic biliary self-expandable metallic stent in malignant biliary obstruction with or without sphincterotomy: systematic review and meta-analysis
}

\section{(ㄷ)(우우}

\author{
Authors \\ Alessandro Repici ${ }^{2,5}$, Lorenzo Fuccio ${ }^{3}$ \\ Institutions \\ 1 Gastrointestinal Endoscopy Unit; Humanitas - Mater \\ Domini Castellanza, Italy \\ 2 Humanitas University, Milan, Italy \\ 3 Department of Medical and Surgical Sciences, S. Orsola- \\ Malpighi Hospital, Bologna, Italy \\ 4 New York-Presbyterian Medical Center/Columbia \\ University Medical Center, New York, New York, United \\ States \\ 5 Digestive Endoscopy Unit, Humanitas Research \\ Hospital, Rozzano (MI) Italy
}

Benedetto Mangiavillano ${ }^{1,2}$, Amedeo Montale ${ }^{3}$, Leonardo Frazzoni ${ }^{3}$, Mario Bianchetti ${ }^{1}$, Amrita Sethi ${ }^{4}$,

submitted 11.5.2018

accepted after revision 4.9.2018

\begin{abstract}
Bibliography
DOI https://doi.org/10.1055/a-0752-9956 |

Endoscopy International Open 2019; 07: E26-E35

(c) Georg Thieme Verlag KG Stuttgart · New York

ISSN 2364-3722
\end{abstract}

Corresponding author

Benedetto Mangiavillano, MD, Gastrointestinal Endoscopy

Unit, Humanitas - Mater Domini, Via Gerenzano n. 2,

21053 - Castellanza (VA), 21053 Italy

Fax: +00390331476205 - 381.

bennymangiavillano@gmail.com

\section{ABSTRACT}

Background and aim To assess the rate of adverse events and the technical success rate of biliary stenting with or without EBS.

Methods A literature search up to February 2017 was performed. Studies assessing adverse events (AEs) and technical success rates of stenting with or without EBS were considered.

Results Seven studies (870 patients; 12 treatment arms) were included. Early AEs, i.e. those occurring within 30 days, were significantly lower in no-EBS vs. EBS-group (11\% vs. $20.1 \%$; OR: $0.36,95 \% \mathrm{Cl}: 0.13-1.00)$. Rates of postendoscopic retrograde cholangiopancreatography (ERCP) pancreatitis were not significantly different in the two groups (no-EBS vs. EBS: $6.1 \%$ vs $5 \%$; OR: 1.33 , $95 \% \mathrm{Cl}$ : $0.68-2.59)$. The rate of bleeding was significantly lower in patients without EBS (no-EBS vs EBS: $0 \%$ vs $5 \%$; OR: 0.12 , $95 \% \mathrm{Cl}: 0.03-0.45)$. Rates of cholangitis were significantly lower in patients without EBS (no-EBS vs. EBS: $3.3 \%$ vs. 7.4\%; OR: 0.38, 95\%Cl: $0.17-0.83$ ). Both late AEs and mortality rates did not significantly differ between no-EBS and EBS patients (19.9\% vs. $18.9 \%$; OR: 0.93 , $95 \% \mathrm{Cl}$ : $0.56-$ 1.53 , and $2.5 \%$ vs. $2.9 \%$; OR: $1.18,95 \% \mathrm{Cl}: 0.22-6.29$, respectively). The technical success rate for stent insertion also did not differ (98\% vs. $97.6 \%$; OR: 1.05 , $95 \% \mathrm{Cl}$ : $0.42-$ 2.63).

Conclusion EBS seems to be associated, in the first 30 days after the procedure, with an increased risk of cholangitis and bleeding. No difference was observed in the rate of post-ERCP pancreatitis.

\section{Introduction}

Pancreatic, gallbladder and bile duct neoplasia are the most common causes of malignant biliary obstruction (MBO) [1]. In cases of advanced unresectable cancer, the prognosis is poor, and a recent study reported a median survival post-biliary drain insertion of 46 days, with 1-, 3-, and 6-month survival rates of $64.7 \%, 26.5 \%$, and $7.4 \%$ respectively [2]. In these cases, biliary decompression with placement of an endoscopic or percuta- neous stent is a critical form of palliative treatment. This drainage can be performed using either plastic stents (PS) or self-expandable metal stents (SEMS) [3].

Endoscopic transpapillary biliary stenting via endoscopic retrograde cholangiopancreatography (ERCP) is considered to be the treatment of choice in relieving jaundice due to MBO [4]. When performing ERCP with stent placement, endoscopic biliary sphincterotomy (EBS) is commonly performed after gaining access to the bile duct. However, the necessity of per- 
forming EBS during palliative biliary stent placement in MBO remains a question. There are several adverse events (AEs) related to ERCP with and without EBS including post-ERCP pancreatitis (PEP), bleeding, cholangitis, and perforation. The rationale for performing EBS prior to stent placement is to facilitate access to bile duct and decrease occurrence of PEP, both by exposing the landmarks of the septum, thus separating biliary and pancreatic ducts, and by reducing tension at the pancreatic duct orifice. However, there is currently conflicting evidence as to whether EBS reduces risk of PEP during palliative biliary stent placement in MBO [5]. In a recent meta-analysis by Sofi et al., there were no significant differences in the rate of PEP in patients with benign or malignant biliary obstruction undergoing biliary stent placement, with and without EBS [6]. Contrarily, in a meta-analysis by Cui et al., the authors concluded that EBS before stenting actually reduced incidence of PEP [7]. However, these results were largely influenced by an old study from $\mathrm{Di}$ Giorgio et al., but in the absence of significantly statistical differences [8].

The main aim of the current study was to systematically compare risk of AEs after biliary stenting in patients with malignant biliary obstruction, with and without biliary sphincterotomy.

\section{Methods}

\section{Data sources, search strategy and quality assessment}

We performed a comprehensive literature search by using PubMed, SCOPUS, Google Scholar and the Cochrane Central Register of Clinical Trials (up to February 2017) to identify fulltext studies evaluating risk of AEs of biliary stent positioning, with and without endoscopic sphincterotomy, in patients with unresectable MBO. Electronic searches were supplemented by manual searches of references of included studies and review articles. Details on the search strategy are reported in Appendix 1.

Quality was assessed by the modified Newcastle-Ottawa Scale for non-randomized studies, ranging from 0 (low-quality) to 5 (high-quality) [9]. Two reviewers (AM, LF) assessed quality measures for included studies and discrepancies were adjudicated by collegial discussion. The statistical review of the study was performed by a biomedical statistician.

\section{Inclusion criteria}

Only comparative studies in which patients underwent biliary stent placement for relief of unresectable MBO, with and without endoscopic sphincterotomy, reporting data on the procedure-related AEs, were included. Prospective and retrospective studies published as full text in English language were considered. Abstracts published in the proceedings of international congresses were not included. Three review authors (BM, AM, LF) independently screened the titles and abstracts yielded by the search against the inclusion criteria.

\section{Exclusion criteria}

Studies including patients with benign biliary obstruction treated by stent placement were excluded, as well as studies published in non-English language or in abstract form.

In case of mixed population, only studies providing data stratified according to the type of obstruction (malignant vs. benign obstruction) were considered. Full texts were retrieved for all abstracts meeting the inclusion criteria or if there was any uncertainty, and evaluated by pairs of review authors. Disagreements were resolved through collegial discussion among all the authors. The reasons for excluding trials were recorded. When there were multiple articles for a single study, we used the latest publication and supplemented it, if necessary, with data from the more complete version.

\section{Data extraction}

The following data were extracted for each study: publication status, study design and location (country), number of participating centers, study population, enrollment periods, patient characteristics (average age, gender), indication for ERCP, AEs and timing of occurrence (early AEs occurring within 30 days since placement and late AEs occurring thereafter), type of $\mathrm{AEs}$, number of patients in follow up, mean period of follow up.

\section{Outcomes assessment}

The primary outcome was risk of AEs, including: 1 ) early AEs (as defined in Cotton et al. [10] defined as occurring within 30 days from stent insertion, i.e. post-ERCP pancreatitis, early bleeding, duodenal perforation, early cholangitis, and early mortality; and 2) late AEs (occurred greater than 30 days post-procedure). These included stent occlusion, stent migration and late cholangitis. Mortality was also evaluated. The secondary outcome was the technical success, defined as the rate of successful biliary stent insertion.

\section{Statistical analysis}

As the outcomes were dichotomous events, we computed the odds ratio (OR) and its $95 \%$ confidence interval $(95 \% \mathrm{Cl})$. Effect size estimates (i. e. OR) were pooled by means of a random effects model in case of heterogeneity across studies, otherwise a fixed effect model was used [11]. We performed a series of sensitivity analyses by excluding one study at a time to evaluate the influence of individual studies on the outcomes. Statistical heterogeneity was measured with the $\mathrm{I}^{2}$ statistic (high heterogeneity level: $>50 \%$ ) and tested using the $Q^{2}$ test (statistical significance cut-off: $P<0.1$ ). Publication bias was not evaluated because fewer than 10 studies were finally available for the analysis. All the analyses were performed by using R statistical software with package Metafor.

\section{Results}

The literature search resulted in 956 articles. After exclusion of review articles, editorials, and case reports, 14 papers were assessed via full text for eligibility. Thus seven studies, comprising a total of 870 patients (range: $74-200$ patients) comparing 
metallic stent positioning for $\mathrm{MBO}$ with and without endoscopic sphincterotomy were included [ $>$ Supplementary Fig. 1]. Details of the included studies are summarized in $\triangleright$ Table 1 and the main findings are summarized in $>$ Table 2 . In none of the selected studies did the patients undergo chemo or pancreatic stent prophylaxis for post-ERCP pancreatitis. Moreover, none of these patients underwent any dilation (mechanical or pneumatic) before stenting.

\section{Early adverse events ( $<30$ days)}

No significant difference in the rate of post-ERCP pancreatitis (PEP) was found comparing the no-EBS group (29/392, 7.3\%) vs EBS group $(27 / 404,6.7 \%)$, with an OR of $1.18(95 \% \mathrm{Cl}$ : $0.66-2.12)$ and low heterogeneity between studies $\left(I^{2}=36 \%\right.$; Q: $8, P=0.16)$ ( $\triangleright$ Fig. 1).

Four studies reported the rate of clinically significant early bleeding, which developed in 0/255 patients in no-EBS group versus 12/208 (5.8\%) subjects in the EBS group, yielding a significantly lower risk in the no-EBS arm (OR: 0.11; $95 \% \mathrm{CI}, 0.02-$ $0.51)$, with a low level of heterogeneity (I2: $0 \%$; $: 2, P=0.62)$. ( Fig. 2).

As addressed by two of the seven included studies, no significant differences were found in the rate of duodenal perforation after ERCP without or with EBS (1/137, $0.7 \%$ vs. 4/137, 2.9\%; OR: $0.48 ; 95 \% \mathrm{Cl}: 0.05-4.20)$, with high heterogeneity $\left(\mathrm{I}^{2}: 58\right.$ $\%, \mathrm{Q}: 2, P=0.12$ ).

Early cholangitis developed in $13 / 82(15.8 \%)$ patients in noEBS arm versus $25 / 79$ (31.6\%) subjects in the EBS arm, yielding a significantly lower risk in the no-EBS group (OR: $0.33 ; 95 \% \mathrm{Cl}$ : $0.14-0.78)$ with low heterogeneity $\left(I^{2}=0 \%\right.$; $\left.0.4, P=0.96\right)$ ( Fig. 3).
Two studies assessed the rate of early mortality, which was $0 \%$ in both treatment groups, yielding no significant difference (OR: 0.57; $95 \% \mathrm{Cl}: 0.04-9.33)$, with low heterogeneity $\left(\mathrm{I}^{2}=0 \%\right.$; $\mathrm{Q}: 0.4, P=0.74)$.

Details on the reported early AEs stratified according to the treatment groups are reported in \ Supplementary Table 1.

\section{Late adverse events (>30 days)}

Rates of stent occlusion, stent migration, late cholangitis, and mortality in the no-EBS and EBS groups are reported in - Supplementary Table2. There was no significantly increased risk of developing any of these late AEs when comparing the two groups.

\section{Technical success}

Overall, based on the seven studies included, the rate of biliary stent insertion was $427 / 429$ patients $(99.5 \%)$ in the no-EBS group versus $437 / 441$ (99.1\%) in the EBS arm, yielding no association with technical success of stent insertion (OR: 1.38; $95 \%$ $\mathrm{Cl}, 0.43-4.48)$, with a low level of heterogeneity between studies ( $I^{2}=0 \%$; Q: $\left.1, P=0.99\right)$ ( $\triangleright$ Fig. 4$)$.

\section{Discussion}

Sphincterotomy is a maneuver commonly performed during ERCP for stent placement in malignant biliary obstruction. However, the benefit of performing EBS during a procedure for palliative stenting remains unclear. Both individual studies and meta-analyses comparing outcomes of EBS vs no-EBS in benign and malignant disease have shown conflicting results. To answer this question in the case of MBO in unresectable lesions,

- Table 1 Details of the included studies.

\begin{tabular}{|c|c|c|c|c|c|c|c|c|}
\hline \multirow[t]{2}{*}{ Author } & \multirow[t]{2}{*}{ Year } & \multirow[t]{2}{*}{ Design } & \multirow{2}{*}{$\begin{array}{l}\text { Stent } \\
\text { type }\end{array}$} & \multirow{2}{*}{$\begin{array}{l}\text { Total } \\
\text { patients }\end{array}$} & \multicolumn{2}{|c|}{ Sphincterotomy arm (n) } & \multicolumn{2}{|c|}{ No sphincterotomy arm (n) } \\
\hline & & & & & $\begin{array}{l}\text { Total patients } \\
\text { (sphinctero- } \\
\text { tomy arm) }\end{array}$ & $\begin{array}{l}\text { Stent insertion } \\
\mathbf{n}(\%)\end{array}$ & $\begin{array}{l}\text { Total patients } \\
\text { (no } \\
\text { sphinctero- } \\
\text { tomy arm) }\end{array}$ & $\begin{array}{l}\text { Stent insertion } \\
\text { n (\%) }\end{array}$ \\
\hline $\begin{array}{l}\text { Artifon } \\
\text { et al. [20] }\end{array}$ & 2008 & $\begin{array}{l}\text { Prospective } \\
\text { RCT }\end{array}$ & $\begin{array}{l}\text { Metallic } \\
\text { stent }\end{array}$ & 74 & 37 & $37(100 \%)$ & 37 & $37(100 \%)$ \\
\hline $\begin{array}{l}\text { Banerjee } \\
\text { et al. [18] }\end{array}$ & 2011 & $\begin{array}{l}\text { Observational } \\
\text { study }\end{array}$ & $\begin{array}{l}\text { Metallic } \\
\text { stent }\end{array}$ & 104 & 27 & $27(100 \%)$ & 77 & $77(100 \%)$ \\
\hline $\begin{array}{l}\text { Zhou } \\
\text { et al. [16] }\end{array}$ & 2012 & $\begin{array}{l}\text { Prospective } \\
\text { RCT }\end{array}$ & $\begin{array}{l}\text { Metallic } \\
\text { stent }\end{array}$ & 82 & 41 & $41(100 \%)$ & 41 & $41(100 \%)$ \\
\hline $\begin{array}{l}\text { Kawakubo } \\
\text { et al. [5] }\end{array}$ & 2012 & $\begin{array}{l}\text { Observational } \\
\text { study }\end{array}$ & $\begin{array}{l}\text { Metallic } \\
\text { stent }\end{array}$ & 257 & 144 & $144(100 \%)$ & 113 & $113(100 \%)$ \\
\hline $\begin{array}{l}\text { Nakahara } \\
\text { et al. [17] }\end{array}$ & 2013 & $\begin{array}{l}\text { Observational } \\
\text { study }\end{array}$ & $\begin{array}{l}\text { Metallic } \\
\text { stent }\end{array}$ & 79 & 38 & $38(100 \%)$ & 41 & $41(100 \%)$ \\
\hline $\begin{array}{l}\text { Shimizu } \\
\text { et al. [19] }\end{array}$ & 2013 & $\begin{array}{l}\text { Observational } \\
\text { study }\end{array}$ & $\begin{array}{l}\text { Metallic } \\
\text { stent }\end{array}$ & 74 & 54 & $54(100 \%)$ & 20 & $20(100 \%)$ \\
\hline $\begin{array}{l}\text { Hayashi } \\
\text { et al. [21] }\end{array}$ & 2015 & $\begin{array}{l}\text { Prospective } \\
\text { RCT }\end{array}$ & $\begin{array}{l}\text { Metallic } \\
\text { stent }\end{array}$ & 200 & 100 & $96(96 \%)$ & 100 & $98(98 \%)$ \\
\hline
\end{tabular}


Table 2 Main findings of the meta-analyses.

\begin{tabular}{|c|c|c|c|}
\hline Outcome & Rate in No-EBS group & Rate in EBS group & OR (95\% CI) \\
\hline Technical success & $427 / 429(99.5 \%)$ & $437 / 441$ (99.1\%) & $1.38(0.43-4.48)$ \\
\hline Overall early adverse events & $39 / 296(13.2 \%)$ & $62 / 243(25.6 \%)$ & $0.28(0.07-1.08)$ \\
\hline Post-ERCP pancreatitis & $29 / 392$ & $27 / 404$ & $1.18(0.66-2.12)$ \\
\hline Early bleeding & $0 / 255$ & $12 / 208(5.8 \%)$ & $0.11(0.02-0.51)$ \\
\hline Duodenal perforation & $1 / 137(0.7 \%)$ & $4 / 137(2.9 \%)$ & $0.48(0.05-4.20)$ \\
\hline Early cholangitis & $13 / 82(15.8 \%)$ & $25 / 79(31.6 \%)$ & $0.33(0.14-0.78)$ \\
\hline Early mortality & $0 / 118$ & $0 / 65$ & $0.57(0.04-9.33)$ \\
\hline Late adverse events & $35 / 155(22.6 \%)$ & $22 / 105(21 \%)$ & $0.43(0.48-1.80)$ \\
\hline Stent occlusion & $18 / 155(11.6 \%)$ & $12 / 105(11.4 \%)$ & $0.90(0.40-2.03)$ \\
\hline Stent migration & $7 / 155$ (4.5\%) & $8 / 102(7.8 \%)$ & $0.71(0.19-2.62)$ \\
\hline
\end{tabular}

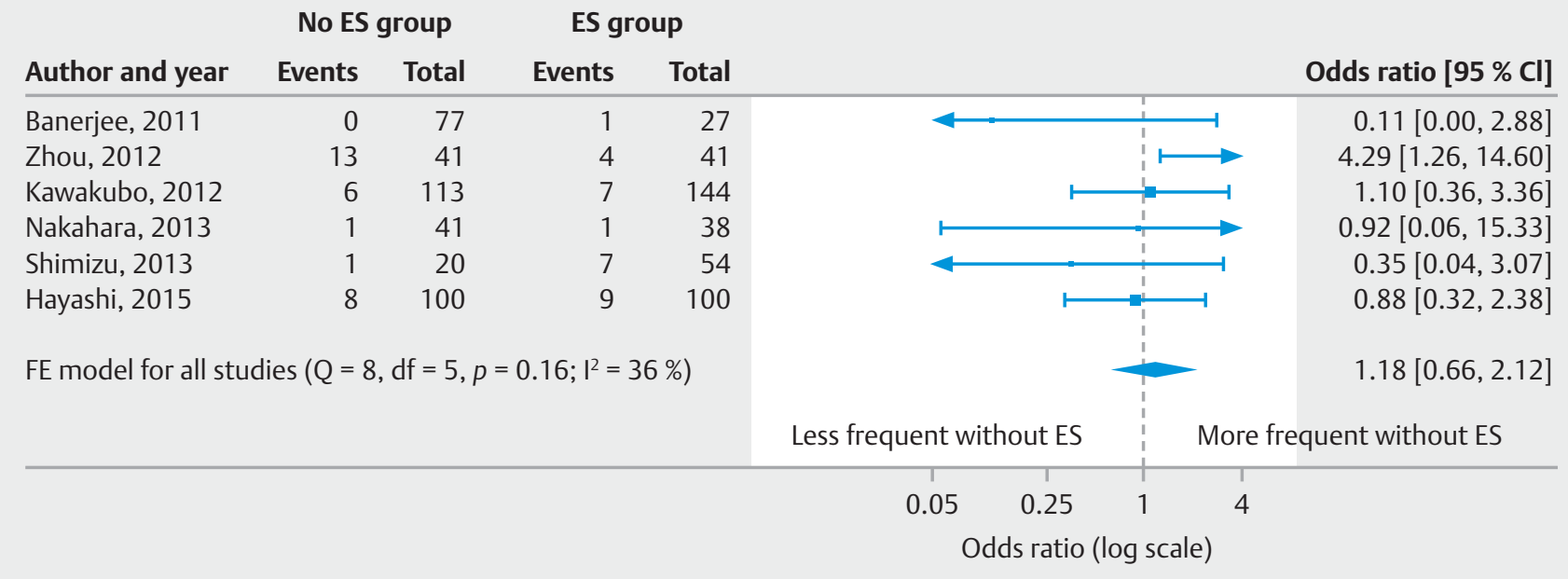

Fig. 1 Forest plot of post-ERCP pancreatitis rates. Low heterogeneity between studies was detected (I2=31.9\%; Q: 6.6, P=0.254).

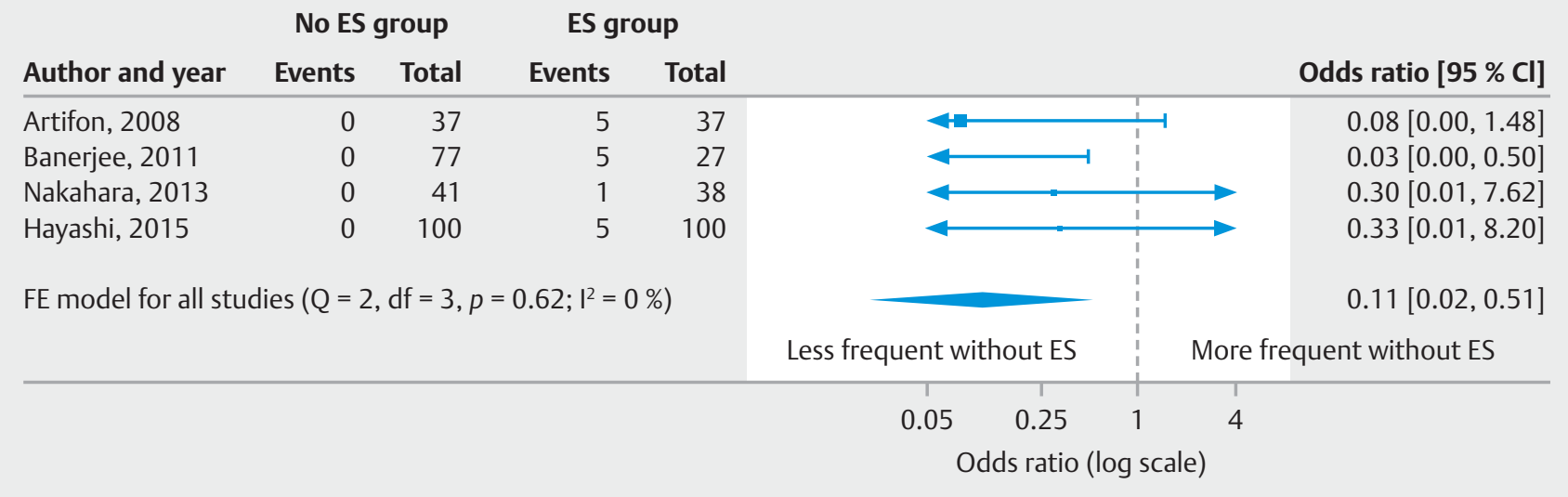

Fig. 2 Forest plot of post-ERCP early bleeding rates. A low level of heterogeneity was observed (I2=0\%; Q: 1.8, P=0.772). 


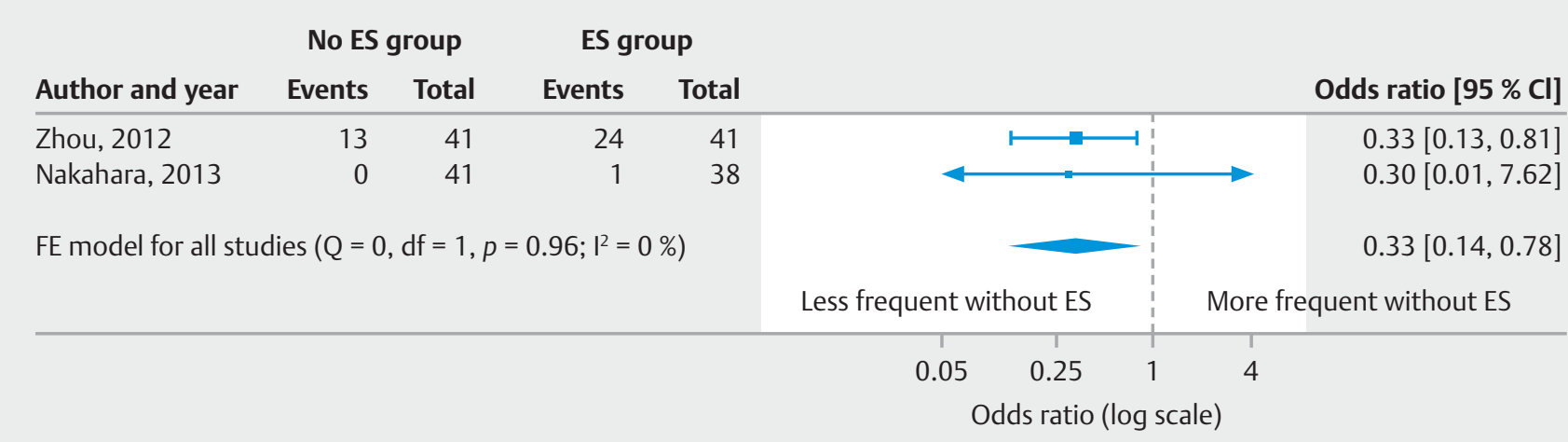

Fig. 3 Forest plot of post-ERCP early cholangitis rates. A low between-study heterogeneity was detected (I2=0\%; Q: $0.8, P=0.976)$.

\begin{tabular}{|c|c|c|c|c|c|c|c|}
\hline \multirow[b]{2}{*}{ Author and year } & \multicolumn{2}{|c|}{ No ES group } & \multicolumn{2}{|c|}{ ES group } & & & \multirow[b]{2}{*}{ Odds ratio [95 \% Cl] } \\
\hline & Events & Total & Events & Total & & & \\
\hline Artifon, 2008 & 37 & 37 & 37 & 37 & 4 & $\rightarrow$ & $1.00[0.02,51.73]$ \\
\hline Banerjee, 2011 & 77 & 77 & 27 & 27 & $\longmapsto$ & $\rightarrow$ & $2.82[0.05,145.49]$ \\
\hline Zhou, 2012 & 41 & 41 & 41 & 41 & $\leftarrow$ & $\rightarrow$ & $1.00[0.02,51.60]$ \\
\hline Kawakubo, 2012 & 113 & 113 & 144 & 144 & 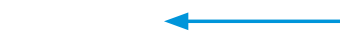 & $\rightarrow$ & $0.79[0.02,39.89]$ \\
\hline Nakahara, 2013 & 41 & 41 & 38 & 38 & $\leftarrow$ & $\rightarrow$ & $1.08[0.02,55.67]$ \\
\hline Shimizu, 2013 & 20 & 20 & 54 & 54 & $\leftarrow$ & $\rightarrow$ & $0.38[0.01,19.59]$ \\
\hline Hayashi, 2015 & 98 & 100 & 96 & 100 & & $\stackrel{1}{\longrightarrow} \longrightarrow$ & $2.04[0.37,11.41]$ \\
\hline \multicolumn{7}{|c|}{ FE model for all studies ( $\left.Q=1, d f=6, p=0.99 ; I^{2}=0 \%\right)$} & $1.38[0.43,4.48]$ \\
\hline & & & & & Less frequent without ES & \multicolumn{2}{|c|}{ More frequent without ES } \\
\hline & & & & & 0.05 & 1 & \\
\hline & & & & \multicolumn{4}{|c|}{ Odds ratio (log scale) } \\
\hline
\end{tabular}

Fig. 4 Forest plot of technical success rates, i. e. stent insertion rates. A low level of heterogeneity between studies was observed $(12=0 \%$; $1.3, P=0.932$ ).

a meta-analysis was performed that included seven studies and 870 patients. Our results demonstrated that no EBS was associated with a decreased risk of overall early AEs, cholangitis and clinically significant bleeding compared to cases in which EBS was performed. Meanwhile, there were no differences in other commonly reported ERCP AEs such as pancreatitis, perforation or mortality. Furthermore, there were no improvements in technical success of stent placement when EBS was performed. Therefore, a conclusion that can be drawn from this systematic review is that endoscopic biliary sphincterotomy may not be justified or necessary prior to stent placement for palliative treatment of MBO.

We feel that our results are relevant for several reasons. This analysis provides an evidence-based approach to assist with standardization of maneuvers performed during ERCP with palliative biliary stent placement. Indeed, by reducing risk of AEs such as bleeding and cholangitis, which can often require prolonged hospitalization and treatment with additional procedures, avoiding sphincterotomy before stent insertion might reduce the overall cost of the procedure and length of hospital stay. In our opinion, one of the supposed mechanisms of cholangitis in patients with EBS is the inflammatory ingrowth and overgrowth of tissue occluding the stent, caused by tissue regeneration from the cut papilla. It can be more frequent especially if the stent is uncovered or, if the stent is fully-covered, it could be happen if the distal end is very close to the papillary orifice.

Regarding the lack of difference in technical success of stent placement, these results support the recommendation that sphincterotomy should be preserved for specific indications that focus on improving access or orifice size at the level of the papilla, such as choledocholithiasis, papillary stenosis, or multiple stent placement. Malignant biliary strictures are generally narrow and rigid, especially in tumors involving the head of the pancreas, and EBS has no relationship with stent insertion through the stricture proximal to the papilla.

Another reason that has been cited when advocating for prestenting EBS was the suggested lower incidence of post-ERCP 
pancreatitis (PEP) $[12,13]$ when sphincterotomy was performed [14]. According to Simmons et al. [15], the proposed mechanism of PEP in the absence of EBS is pancreatic duct orifice obstruction by the biliary stent. Results of the studies published in literature about risk of PEP in patients with distal malignant biliary obstruction $[8,12,15,-20]$ are conflicting, however, our data do not support the hypothesis of an increased risk of PEP without sphincterotomy.

The significantly increased rate of clinically significant bleeding in the EBS group was an expected result. This, coupled with a failure to offer improvement in technical success of stent placement, thus raising objection to necessity of pre-stenting EBS. Indeed, in this meta-analysis, bleeding after stent placement for $\mathrm{MBO}$ was about $0 \%$ in patients without EBS, whereas it ranged from $2.6 \%$ to $18.5 \%$ in those receiving EBS $[8,12,15$, $17-21$ ]. In our opinion, a possible explanation for increased risk of bleeding in the EBS-group could be that patients underwent EBS after an initial failed cannulation, with a successive pre-cut (after completed with an EBS), which that represents a high risk of bleeding, but in the analyzed studies there is no mention of pre-cut access to the common bile duct. If the sphincterotomy is large, the pressure of the stent to tampon the bleeding is low to stop an eventual post-EBS bleed. Moreover, this issue is valid only for the FCSEMS, because if the stent is uncovered, the meshes of the metal stent can traumatize the cut mucosa, promoting bleeding.

The current meta-analysis presents several limitations. First of all, only limited data on this subject are available and therefore our conclusion could be limited. After applying the strict selection criteria, only seven studies were finally included. Clinical and statistical heterogeneity was ascertained, as both plastic and SEMS were used in the studies, and concerning the latter group, either uncovered, partially-covered or FCSEMS were implemented. Furthermore, the limited number of patients and arms of treatment did not allow stratification of outcomes according to the type of stent used. Another limitation is that few studies provided results regarding late AEs such as late cholangitis and mortality, thus the estimates regarding these specific outcomes might not be conclusive. We limited our search only to full text published in English and this could have introduced language and publication bias. The few included studies precluded any statistical analysis of the presence of publication bias, such as development of a funnel plot or Egger's tests.

\section{Conclusion}

In conclusion, our meta-analysis showed that performing endoscopic biliary sphincterotomy before stent placement for palliation in patients with neoplastic biliary obstruction may no longer be justified. In fact, given no additional benefit in technical success nor in prevention of post-ERCP pancreatitis, but rather significantly increased risks of overall early AEs of early clinically significant bleeding and early cholangitis, perhaps it is time for sphincterotomy prior to biliary palliative stenting to be abandoned. Further prospective randomized trials are needed to definitively address this issue.

\section{Appendix 1}

We identified studies using the following medical subject headings (MeSH) and keywords including: "Endoscopic retrograde cholangiopancreatography”, "ERCP”, "Sphincterotomy”, "Pancreas", "Neoplasms".

In detail, we implemented the following PubMed search strategy:

1. "Adverse effects" (Mesh) AND "Sphincterotomy endoscopic (Mesh)" AND "Self-expandable metallic stent" (Mesh) AND "Pancreas" (Mesh).

2. "Cholangiopancreatography, endoscopic retrograde" (Mesh) AND "Sphincterotomy, endoscopic" (Mesh) AND "Jaundice, obstructive" (Mesh).

3. "Neoplasm" (Mesh) AND "Stents" (Mesh) AND "Biliary tract" (Mesh) AND "Sphincterotomy, endoscopic" (Mesh).

\section{Competing interests}

None

\section{References}

[1] Castells A, Kroser J, Rustgi AK. Gastrointestinal neoplasms. In: Beers $\mathrm{MH}$, Berkow R, eds. The Merck manual of geriatrics. 3rd ed. Whitehouse Station, NJ: Merck; 2000: 1134-1153

[2] Tuqan W, Innabi A, Alawneh A et al. Prediction of survival following percutaneous biliary drainage for malignant biliary obstruction. J Transl Int Med 2017; 30: 127 -131

[3] Mangiavillano B, Pagano N, Baron TH et al. Outcome of stenting in biliary and pancreatic benign and malignant diseases: A comprehensive review. World J Gastroenterol 2015; 21: 9038 - 9054

[4] Mangiavillano B, Pagano N, Baron TH et al. Biliary and pancreatic stenting: Devices and insertion techniques in therapeutic endoscopic retrograde cholangiopancreatography and endoscopic ultrasonography. World J Gastrointest Endosc 2016; 8: 143-56

[5] Kawakubo K, Isayama H, Nakai Y et al. Risk factors for pancreatitis following transpapillary self-expandable metal stent placement. Surg Endosc 2012; 26: $771-776$

[6] Sofi AA, Nawras A, Alaradi OH et al. Does endoscopic sphincterotomy reduce the risk of post-endoscopic retrograde cholangiopancreatography pancreatitis after biliary stenting? A systematic review and meta-analysis Dig Endosc 2016; 28: 394-404

[7] Cui PJ, Yao J, Zhao Y] et al. Biliary stenting with or without sphincterotomy for malignant biliary obstruction: a meta-analysis. World ] Gastroenterol 2014; 20: 14033-14039

[8] Di Giorgio P, De Luca L. Comparison of treatment outcomes between biliary plastic stent placement with and without endoscopic sphincterotomy for inoperable malignant common bile duct obstruction. World J Gastroenterol 2004; 10: 1212-1214

[9] Well GA, Shea B, O'Connell J et al. The Newcastle-Ottawa scale (NOS) for assessing the quality of non randomized studies in meta-analysis. Available at: http://www.ohri.ca/programs/clinical_epidemiology/ oxford.asp Accessed: 12 August 2016

[10] Cotton PB, Garrow DA, Gallagher J et al. Risk factors for complications after ERCP: a multivariate analysis of 11,497 procedures over 12 years. Gastrointest Endosc 2009; 70: $80-88$ 
[11] Der Simonian R, Laird N. Meta-analysis in clinical trials. Control Clin Trials 1986; 7: $177-188$

[12] Tarnasky PR, Cunningham JT, Hawes RH et al. Transpapillary stenting of proximal biliary strictures: does biliary sphincterotomy reduce the risk of postprocedure pancreatitis? Gastrointest Endosc 1997; 45: $46-51$

[13] Simmons DT, Petersen BT, Gostout C] et al. Risk of pancreatitis following endoscopically placed large-bore plastic biliary stents with and without biliary sphincterotomy for management of postoperative bile leaks. Surg Endosc 2008; 22: 1459-1463

[14] Ang TL, Kwek AB, Lim KB et al. An analysis of the efficacy and safety of a strategy of early precut for biliary access during difficult endoscopic retrograde cholangiopancreatography in a general hospital. J Dig Dis 2010; 11: $306-312$

[15] Simmons DT, Petersen BT, Gostout CJ et al. Risk of pancreatitis following endoscopically placed large-bore plastic biliary stents with and without biliary sphincterotomy for management of postoperative bile leaks. Surg Endosc 2008; 22: 1459-1463

[16] Zhou H, Li L, Zhu F et al. Endoscopic sphincterotomy associated cholangitis in patients receiving proximal biliary self-expanding metal stents. Hepatobiliary Pancreat Dis Int 2012; 11: 643 - 649
[17] Nakahara K, Okuse C, Suetani K et al. Covered metal stenting for malignant lower biliary stricture with pancreatic duct obstruction: is endoscopic sphincterotomy needed? Gastroenterol Res Pract 2013; 2013: 375613

[18] Banerjee N, Hilden K, Baron TH et al. Endoscopic biliary sphincterotomy is not required for transpapillary SEMS placement for biliary obstruction. Dig Dis Sci 2011; 56: 591 - 595

[19] Shimizu S, Naitoh I, Nakazawa T et al. Predictive factors for pancreatitis and cholecystitis in endoscopic covered metal stenting for distal malignant biliary obstruction. J Gastroenterol Hepatol 2013; 28: $68-72$

[20] Artifon EL, Sakai P, Ishioka S et al. Endoscopic sphincterotomy before deployment of covered metal stent is associated with greater complication rate: a prospective randomized control trial. J Clin Gastroenterol 2008; 42: 815-819

[21] Hayashi T, Kawakami H, Osanai M et al. No benefit of endoscopic sphincterotomy before biliary placement of self-expandable metal stents for unresectable pancreatic cancer. Clin Gastroenterol Hepatol 2015; 13: $1151-8 . e 2$ 
Literature search

Database: Pubmed, EMBASE, Scopus, Google Scholar,

Cochrane Central Register of Clinical Trials

Publications: Full text, abstract

Design: Retrospective and Prospective

$\downarrow$

958 studies were identified from database

942 studies excluded by titles

16 articles were retrieved for more details and application of inclusion criteria

9 articles excluded

- benign disease: 5

- benign and malignant disease: 3

- malignant disease and plastic stent: 1

$\mathbf{7}$ articles on solely malignant disease included with $\mathbf{1 4}$ treatment arms comparing:

endoscopic sphincterotomy + self-expandable metallic

stent

versus

no endoscopic sphincterotomy + self-expandable

metallic stent

- Supplementary Fig. 1 Flow-chart of the selected studies. 


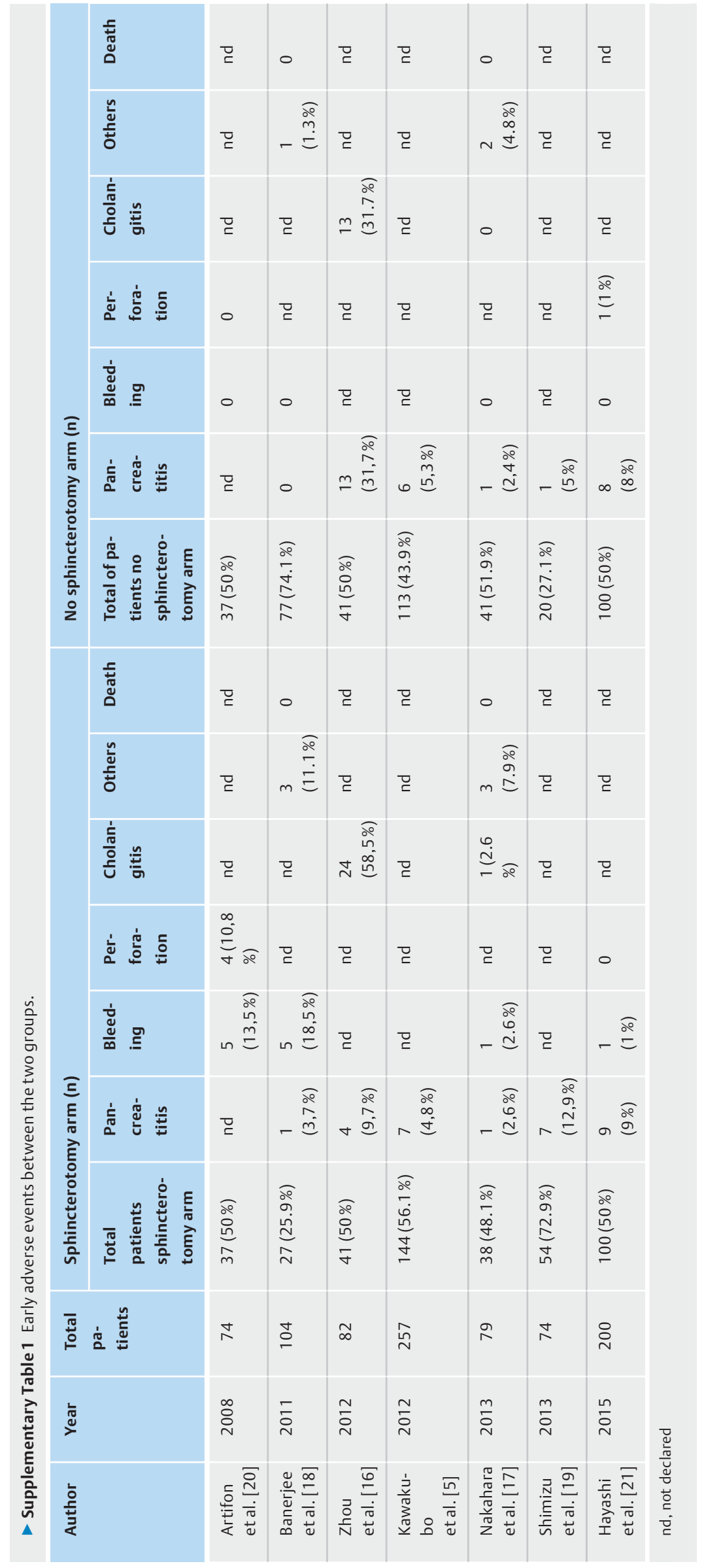




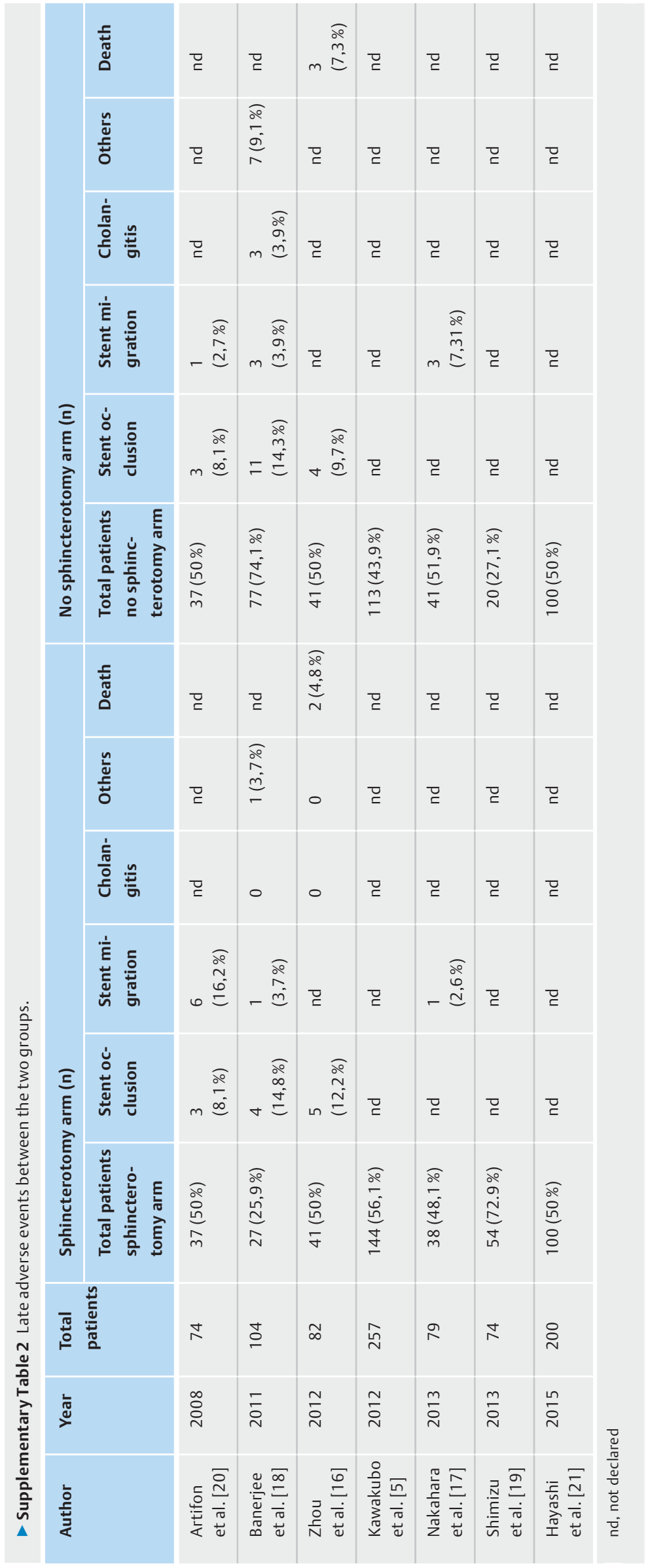

